\title{
Experimental Fluid Mechanics 2016
}

Marienbad, Czech Republic, $15^{\text {th }}-18^{\text {th }}$ November 2016

efm.kez.tul.cz

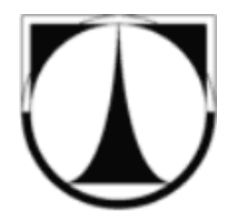

$11^{\text {th }}$ International Conference ,Experimental Fluid Mechanics 2016 ” was held at $15^{\text {th }}-18^{\text {th }}$ November 2016 in The Casino Cultural and Conference Centre in Marienbad, Czech Republic.

The EFM conference is focused on obtaining overviews of projects under investigation and experimental methods used in the field of fluid mechanic and thermodynamic. Its aim is to organize a network of research workers who are interested in experimental, and also theoretical, work in the field of fluid mechanic and thermodynamic. The conference should contribute the creation of closer contacts and sharing experience in application of various experimental methods, preparation and implementation of experiments, processing of results and numerical simulations of experiments.

The main topics of the conference are:

- Experimental methods used in fluid mechanics and thermodynamics.

- Preparation and implementation of experiments.

- Application of numerical simulation for preparation of experiments, comparison of the results obtained by numerical or analytical methods with experiments.

- Processing the results.

- Experiments in the field of compressible and uncompressible fluid flow, stability of flow, heat and mass transfer, cavitation etc.

- Experiments and measuring carried out on power and regulating equipment.

- Cryogenic fluid dynamics.

Members of Sciences Committee are:

- Assoc. Prof. Tomáš Vít - Head of the committee (TU Liberec, Czech Republic)

- Simone Ferrari (University of Cagliari, Italy)

- Jan Hrubý (Academy of Science of Czech Republic)

- Hendric de Lange (Eindhoven Univ. of Technology, Netherlands)

- Václav Kopecký (TU Liberec, Czech Republic)

- Robert Pastuszko (Kielce University of Technology, Poland)

- Kazimierz Peszynski (UTP University of Science and Technology, Poland)

- Ludvík Prášil (TU Liberec, Czech Republic)

- Jaromír Prríhoda (Academy of Science of Czech Republic)

- Rudi Santbergen (Delft University of Technology, Netherlands)

- Ladislav Skrbek (Charles University, Czech Republic)

- Zdeněk Trávníček (Academy of Science of Czech Republic)

- Václav Uruba (Academy of Science of Czech Republic)

- Magda Vestfálová (TU Liberec, Czech Republic)

- An-Bang Wang (National Taiwan University, Taiwan)

- Yoshifumi Yokoi (National Defense Academy of Japan, Japan)

\section{Steering Committee:}

- Petra Dančová - Head of the committee (TU Liberec, Czech Republic)

- Jan Novosád (TU Liberec, Czech Republic)

- Martin Veselý (TU Liberec, Czech Republic) 

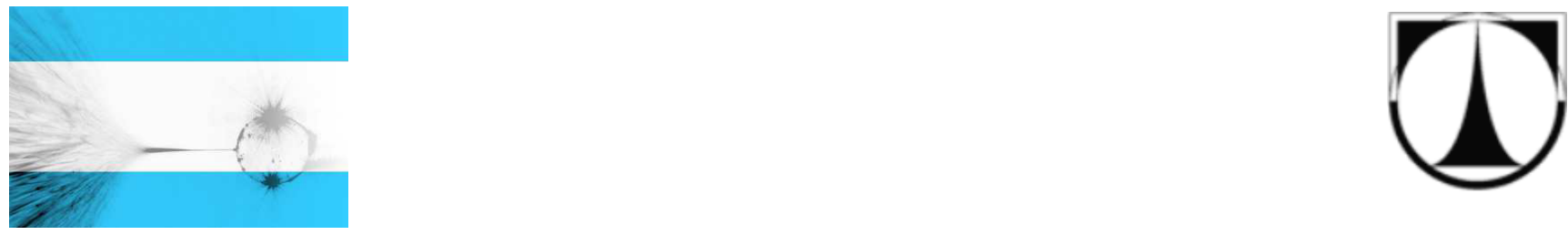

Keynote lectures for 2016 :

- Prof. Simone Ferrari (University of Cagliari, Italy) Image Analysis techniques for the study of turbulent flows

- Prof. Muk Chen Ong (University of Stavanger, Norway)

CFD Applications in Offshore Engineering

List of Sponsors (in alphabetical order):

- DANTEC DYNAMICS GmbH (www.dantecdynamics.com)

- LAVISION (http://www.lavision.de/en/)

- MIT s.r.o. (www.mit-laser.cz)

- TSI GmbH (www.tsi.com)

\section{Conference venue:}

Every year, the organizers want to prepare the conference at nice and interesting place of the Czech Republic. In 2016, the conference venue was Marienbad.

Marienbad means beautiful spa parks, romantic colonnades, charming pavilions, pleasant cafes and cozy hotels. The town is endowed with many healing mineral springs and revels in a unique atmosphere that attracts thousands of visitors every year who come to soak up this atmosphere. Within the town and its surroundings rise around one hundred mineral springs, containing carbon dioxide and mineral salts. They are cold ferrous mineral waters. Drinking treatments mostly use the main 6 mineral springs: Cross (Kř́žový), Rudolf, Karolina, Forest (Lesní), Ambrose and Ferdinand.

The organizers would like to invite you for the next year of the EFM conference, which will be held in Mikulov, November $21^{\text {st }}-24^{\text {th }}, 2017$ (see our web pages efm.kez.tul.cz).

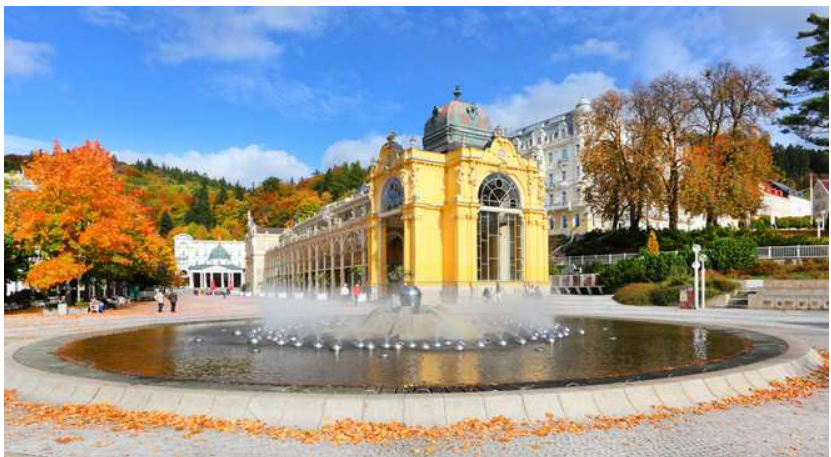

Marienbad

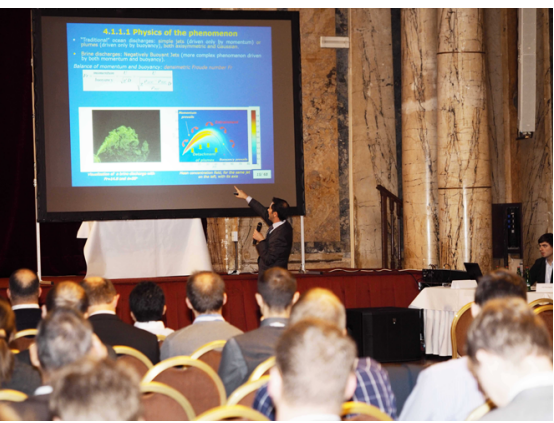

Keynote lecture - prof. Simone Ferrari

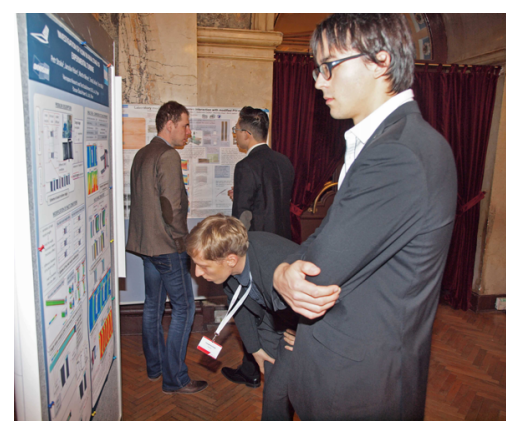

Poster section

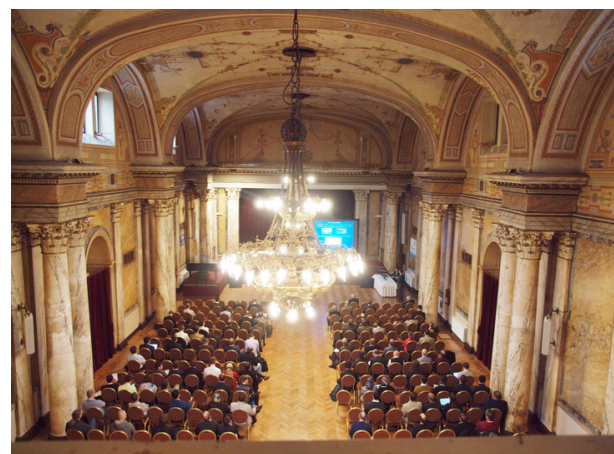

View into Room A 